정규논문 (Regular Paper) 방송공학회논문지 제18권 제4호, 2013년 7월 (JBE Vol. 18, No. 4, July 2013) http://dx.doi.org/10.5909/JBE.2013.18.4.631 ISSN 2287-9137 (Online) ISSN 1226-7953 (Print)

\title{
$\mathrm{HEVC}$ 를 위한 고속 변환 크기 결정방법
}

\author{
강 장 병a), 최 해 철()
}

\section{Early Decision of Transform unit for HEVC}

\author{
Jang-Byung Kang ${ }^{\text {a) }}$ and Haechul Choi ${ }^{\text {a) }}$
}

요 약

본 논문에서는 HEVC (High Efficiency Video Coding)의 복잡도 감소를 위한 고속 변환 크기 결정방법을 제안한다. HEVC는 변환 과정을 결정하는 $\mathrm{TU}$ (transform unit)를 정의하며, TU는 재귀적인 트리구조를 사용하여 여러 개의 하위블록으로 분할할 수 있다. 이와 같은 트리구조의 사용으로 $\mathrm{TU}$ 는 $4 \times 4$ 32x32의 다양한 블록크기를 지원할 수 있고, 이것은 높은 부호화 효율을 얻을 수 있는 핵심 기술이다. 하지만 필연적으로 부호화 복잡도가 증가하게 되고 이러한 부호화 복잡도의 증가는 $\mathrm{HEVC}$ 의 단점 중 하나이다. 제안 방법 은 마지막 0 이 아닌 변환 계수의 위치를 기준으로 변환블록의 에너지 집중도를 판단하고, 에너지 집중도가 충분한 블록이면 하위 블 록으로 분할하지 않을 확률이 높다는 실험결과에 근거하여 $\mathrm{TU}$ 의 분할 여부를 빠르게 결정한다. 실험결과에서 제안방법은 Random_access_Main 모드에 대해 $0.7 \%$ 의 BD-rate 증가로 $18 \%$ 의 부호화 시간을 감소시킬 수 있음을 보인다.

\section{Abstract}

For the emerging High Efficiency Video Coding (HEVC) standard, a fast transform unit (TU) decision method is proposed. HEVC defines the TU representing a region sharing the same transformation, and it allows a residual block to be split into multiple TUs recursively to form a quadtree. By using the quadtree of TUs, HEVC supports various transform sizes from $4 \times 4$ to 32x32. The various sizes of TUs can provide a good coding efficiency, whereas this may increase encoding complexity dramatically. In the assumption that a TU with highly compacted energy is unlikely to be split, the proposed method determines TU sizes according to the position of the last non-zero transform coefficient. In the experimental results, the proposed method reduced $18 \%$ encoding run time with the negligible coding loss of $0.7 \%$ BD-rate for the Random_access case.

Keyword : HEVC, Transform Unit, Early TU termination, Fast encoder

a) 한밭대학교 정보통신공학과 (Hanbat University Multimedia Engineering)

₹ Corresponding Author : 최해철 (Haechul Choi) E-mail: choihc@hanbat.ac.kr Tel: 042-821-1149

₹ 이 연구는 2012년도 정부(교육과학기술부)의 재원으로 한국 연구 재단 의 기초 연구 사업(과제번호: 2010-0023109) 및 교육 과학 기술부와 한국 연구 재단의 지역 혁신 인력 양성 산업 (과제번호: $2012 \mathrm{H} 1 \mathrm{~B} 8 \mathrm{~A}$ 2025982) 의 지원을 받아 수행된 것임.

Manuscript received June 14, 2013 Revised July 24, 2013 Accepted July 24,2013

\section{I. 서 론}

최근 디지털 방송기술과 디스플레이 기기 등의 발전으로 고해상도 비디오 품질에 대한 소비자의 요구가 꾸준히 증 가하고, 이에 따라 기존의 영상 크기를 넘어선 $4 \mathrm{~K} \sim 8 \mathrm{~K}$ 급 초고해상도 영상에 대한 필요성이 대두되고 있담1ㄹㄹ. 또 한 스마트폰 등 모바일 기기에서도 Full HD 급 영상 재생이 
가능하며 기존의 30 프레임 재생율을 넘어선 60 프레임 이 상의 재생율이 요구 되고 있다. 초고해상도 비디오 콘텐츠 들은 기본적으로 기존의 비디오 콘텐츠에 비해 많게는 수 십 배에 달하는 데이터량을 갖게 된다. 이러한 초고해상도 비디오 콘텐츠들의 많은 데이터들을 효과적으로 처리하기 위하여 기존의 H.264/AVC ${ }^{[3]}$ 의 압축 효율을 뛰어넘는 새로 운 비디오 표준이 필요하게 되었고, 이에 따라 국제 비디오 부호화 표준화 단체에서는 2010년 1월 JCT-VC (Joint Collaborative Team on Video Coding)을 설립하여 차세대 비디오 부호화 표준인 $\mathrm{HEVC(High} \mathrm{Efficiency} \mathrm{Video}$ Coding) ${ }^{[4]}$ 에 대한 표준화를 지난 2013년 1월 완료하였다. $\mathrm{HEVC}$ 에 대한 요구 사항[5]으로는 기존에 표준화 완료된 H.264/AVC 대비 뛰어난 압축 성능, 병렬처리, 부호화 복잡 도의 유동성 등이 있다. JCT-VC에서는 표준 및 관련 기술 개발을 위해 HEVC 참조 소프트웨어인 HM-11 (HEVC Test Model $)^{[6]}$ 을 제공하고 있다. HEVC는 기존의 H.264/ $\mathrm{AVC}$ 에 비해 약 $40 \%$ 정도로 객관적 화질측면에서의 높은 부호화 효율 보이고 있다 ${ }^{[7]}$. 하지만 이러한 압축효율은 지 나치게 높은 복잡도를 필연적으로 갖게 되고 이것은 $\mathrm{HEVC}$ 의 주된 단점이라고 할 수 있다. $\mathrm{HEVC}$ 부호화기에서 이전 표준들에 비해 복잡도의 증가가 두드러진 부분은 $\mathrm{CU}$ (Coding Unit) 결정 과정이다. 기존 H.264/AVC에서는 기 본 부호화 블록이 $16 \times 16$ 매크로 블록으로 고정되어 있다. 하지만 $\mathrm{HEVC}$ 에서는 순차적인 트리구조에 의해 $64 \times 64$ 크기에서 8x8 크기까지 각 크기별로 비용을 계산하고 비
용이 가장 적은 크기의 블록을 선택하여 부호화한다. 또 한 $\mathrm{H} .264 / \mathrm{AVC}$ 의 $4 \times 4$ 혹은 $8 \times 8$ 크기의 변환블록과 달리 $\mathrm{HEVC}$ 는 각 크기의 $\mathrm{CU}$ 에 따라 $32 \times 32$ 크기부터 $4 \times 4$ 크기 까지 순차적으로 $\mathrm{TU}$ 의 비용을 계산하며 가장 적은 비용을 갖는 $\mathrm{TU}$ 크기를 선택하여 부호화 한다. 따라서 $\mathrm{HEVC}$ 는 영상의 특성에 따라 여러 크기의 블록으로 나눠질 수 있고, 다양한 크기의 지원은 높은 압축 효율을 보장한다. 그러나 이용 가능한 크기의 블록 조합이 상당히 많기 때문에 최적 의 블록크기를 결정하기 위해 높은 계산 복잡도를 요구하 게 된다.

본 논문의 목적은 상기에서 기술한 TU 크기 결정 과정에 서의 복잡도 감소이며 논문의 구성은 다음과 같다. 먼저 2 장에서는 $\mathrm{HEVC}$ 의 부호화 블록을 결정하는 과정을 살펴본 다. 다음 3 장에서는 제안하는 방법과 이를 뒷받침할 실험결 과와 논리적 근거를 설명하며 4장에서는 제안방법의 성능 분석에 대하여 기술하고 있으며 마지막으로 5 장에서 결론 을 맺는다.

\section{HEVC의 블록 분할 및 기존 고속화 방법}

\section{HEVC 기반 부호화 블록 결정 방법}

$\mathrm{HEVC}$ 의 주요 기술 중 하나는 계층적 재귀 구조를 갖는 코딩트리블록(coding tree block; $\mathrm{CTB}$ )이다. 과거 비디오

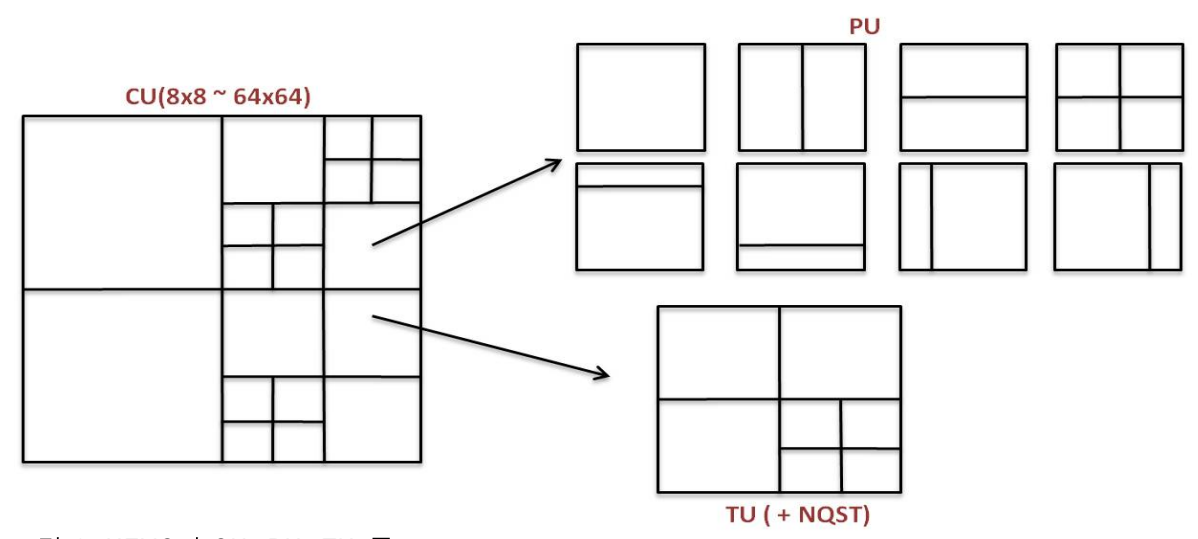

그림 1. HEVC의 $\mathrm{CU}, \mathrm{PU}, \mathrm{TU}$ 구조

Fig. 1. An example of HEVC block partitioning including coding unit, prediction unit, and transfrom unit 
부호화 표준인 H.264/AVC에서 기본블록 단위로 사용되었 던 $16 \times 16$ 고정 크기의 매크로블록 대신, $\mathrm{HEVC}$ 는 계층적 트리 구조인 $\mathrm{CTB}$ 를 통해 가변적 블록 크기인 코딩유닛 (coding unit; $\mathrm{CU}$ ), 예측유닛(prediction unit; PU) 및 변환유 닛(transform unit; TU)을 정의한다 ${ }^{[8]}$. 그림 1 과 같이 $\mathrm{HEVC}$ 는 쿼드트리(quard-tree) 구조를 사용하여 계층에 따라 재귀 적으로 $\mathrm{CU}$ 를 더 작은 유닛으로 분할함으로써 $8 \times 8$ 에서 $64 \times 64$ 의 다양한 블록 크기를 지원한다. 최적의 $\mathrm{CU}$ 크기를 결정하기 위하여 각 $\mathrm{CU}$ 에서 각각의 $\mathrm{PU}$ 크기 및 $\mathrm{TU}$ 크기에 대해 가장 작은 비용을 갖는 블록 크기를 조사한다. 이때 $\mathrm{PU}$ 는 대응하는 $\mathrm{CU}$ 의 크기로부터 다양한 모양의 예측블록 으로 분할하여 비용조사를 하게 되며, TU는 대응하는 $\mathrm{CU}$ 의 크기로부터 $\mathrm{CU}$ 결정 과정과 마찬가지로 재귀적인 트리 구조로 분할을 하여 각각의 크기에 대한 모든 비용을 조사 한다. 따라서 $\mathrm{HEVC}$ 의 부호화 과정은 하나의 $\mathrm{CU}$ 를 조사하 는 과정에서 나올 수 있는 모든 크기의 PU와 TU를 조사하 게 되고, 영상의 특성에 따라 적응적인 블록크기 결정이 가 능하며, 기존 비디오코덱에서 사용할 수 없었던 다양한 형 태의 블록조합을 사용하여 영상을 압축할 수 있다.

임의 크기의 $\mathrm{CU}$ 로부터 최적의 $\mathrm{PU}$ 크기 및 $\mathrm{TU}$ 크기 결 정 방법은 다음 그림 2와 같다. $\mathrm{HEVC}$ 에서 $\mathrm{CU}$ 는 다양한
크기의 PU로 분할될 수 있을 뿐만 아니라, 각 $\mathrm{CU}$ 는 $\mathrm{PU}$ 와 관계없이 쿼드 트리 구조의 TU로 분할될 수 있다. 이때 최 적의 비용을 갖는 $\mathrm{CU}$ 를 찾기 위해 순차적으로 가장 큰 크 기인 LCU(large coding unit)부터 가장 작은 크기인 $\mathrm{SCU}$ (small coding unit)까지 재귀적인 쿼드트리 구조에 따라 비 용을 계산하게 되고, 각 $\mathrm{CU}$ 크기 별로 매번 $\mathrm{PU}$ 의 여러 모 드에 대한 예측비용을 전부 계산하며, 최소크기의 $\mathrm{CU}$ 인 경 우에만 Intra NxN 모드를 수행하여 비용조사를 한다. 각 $\mathrm{PU}$ 에 대한 비용 조사를 할 때, $\mathrm{PU}$ 별로 생성된 잔차신호에 대해 TU의 비용조사 또한 수행한다. TU는 $\mathrm{CU}$ 구조와 마 찬가지로 재귀적인 쿼드트리 구조에 따라 4 개의 하위블록 으로 재귀적으로 분할될 수 있다. 그림 2와 같이 모든 PU 마다 TU 분할 방식을 반복적으로 조사하는 이유는 하나의 $\mathrm{CU}$ 로부터 대응하는 PU의 모드 및 크기에 따른 잔차신호의 특성이 변화하기 때문이다. 결론적으로, 하나의 $\mathrm{CU}$ 에서 각 각의 PU 모드에 따라 잔차신호를 생성하고, 이 잔차신호에 대해 $\mathrm{TU}$ 쿼드 트리의 비용을 전부 계산하여 최적의 $\mathrm{CU}$, $\mathrm{PU}, \mathrm{TU}$ 를 선택한다.

위 그림 2와 같은 방식으로 HEVC는 이전 표준인 H.264/ $\mathrm{AVC}$ 의 고정된 크기인 매크로 블록으로 부호화 하는 경우 보다 더욱 효과적인 부호화가 가능하며 높은 부호화 효율

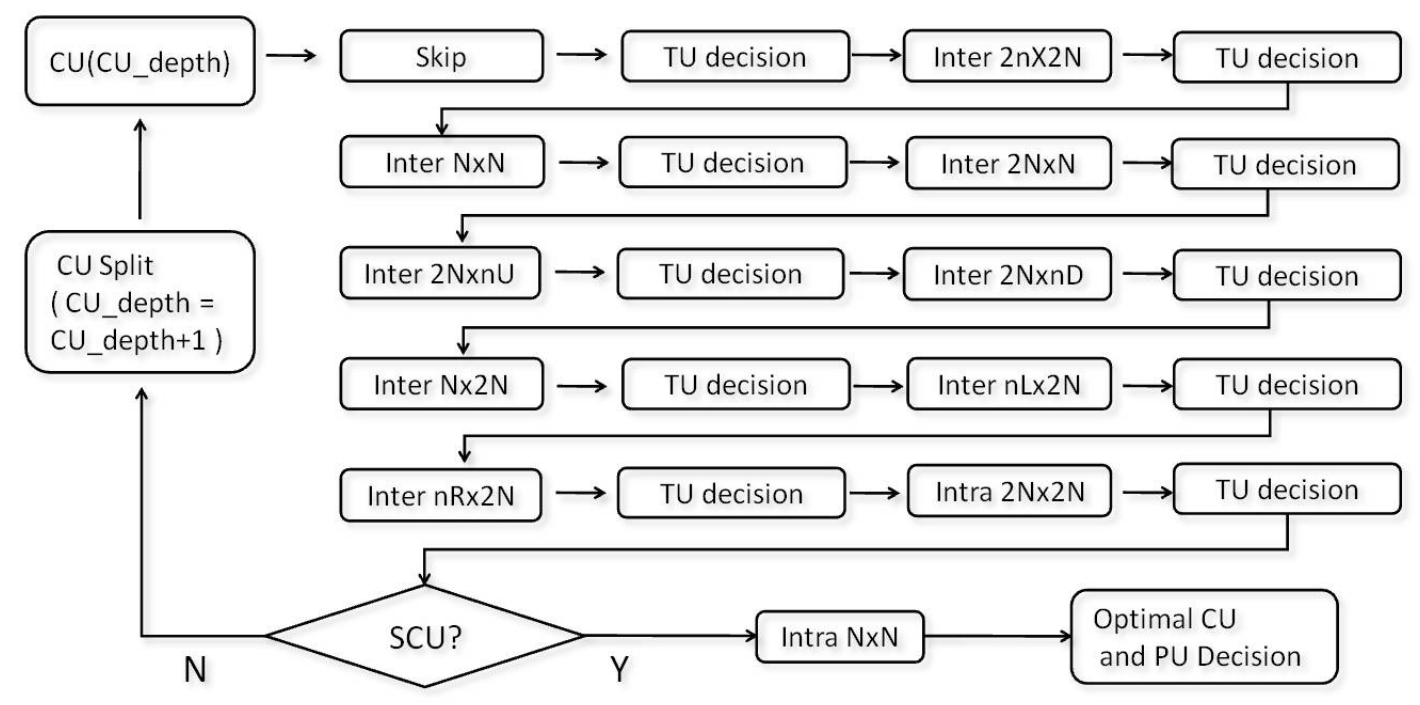

그림 2. 재귀적 $\mathrm{CU}, \mathrm{PU}, \mathrm{TU}$ 결정과정

Fig. 2. A flowchart for HEVC CU, PU, and TU decisions 
을 보장한다. 그러나 부호화 과정에서 허용하는 $\mathrm{CU}$ 및 $\mathrm{PU}$ 의 조합 수가 매우 증가하게 되고, 각 조합에 대하여 최적의 비용을 조사하는 과정에서의 계산 복잡도가 과도하게 요구 된다. 또한 상기에 기술한 바와 같이 잔차신호의 특성적 변 화로 $\mathrm{HEVC}$ 는 반복적인 쿼드트리 구조의 분할을 하며 $\mathrm{TU}$ 에 대한 비용 조사를 하게 되고, TU 결정 과정 또한 과도한 계산 복잡도가 요구된다. 따라서 상기와 같은 $\mathrm{CU}, \mathrm{PU}, \mathrm{TU}$ 결정과정에서 필연적인 복잡도 증가는 해결해야 할 과제이 다.

\section{HEVC 기반 기존 고속화 방법}

상기와 같은 과도한 복잡도의 감소를 위해서, Chen[9]은 Bayesian decision rule을 이용한 고속 CU크기 결정방법을 제안하였다. 이 방법은 상위 $\mathrm{CU}$ 크기에서 하위 4 개 $\mathrm{CU}$ 크 기의 분할에 대해 SATD(sum of absolute transformed difference)값으로 Bayesian decision rule을 적용하여 하위 블 록으로의 분할여부를 판별한다. $\mathrm{Chen}$ 의 고속 $\mathrm{CU}$ 크기 결 정방법은 약 $1.88 \%$ 의 $\mathrm{BD}-\mathrm{rate}$ 증가율로 약 $40 \%$ 정도의 부 호화 복잡도 감소를 보인다. 또한 $\mathrm{Choi}[10]$ 는 $\mathrm{CU}$ 의 조사과 정을 조기 종료하는 방법(Early CU Setting; ECU)을 제안 하였다. 이 방법은 $\mathrm{CU}$ 의 $\mathrm{PU}$ 조사 과정 중 최적 모드가 SKIP 모드로 결정이 되면 하위 블록으로의 분할을 강제로 허용하지 않음으로써 약 $40 \%$ 정도의 부호화 복잡도 감소 를 보였고, 이는 $\mathrm{HM}$ 에 포함되었다. $\mathrm{Yang}[11]$ 은 $\mathrm{CU}$ 의 분할 과정을 조기 결정하는 방법(Early Skip Detection Setting; $\mathrm{ESD}$ )을 제안하였다. 이 방법은 Inter $2 \mathrm{Nx} 2 \mathrm{~N}$ 모드를 조사한 후 Coded Block Flag $(\mathrm{CBF})$ 값이 0 이며 Motion vector difference (MVD)가 $(0,0)$ 값을 갖는 경우 다른 형태의 PU들을 조사하지 않고, 바로 분할하여 다음깊이의 $\mathrm{CU}$ 조사과정을 이어간다. 여기서 $\mathrm{CBF}$ 는 0 이 아닌 잔차 신호의 존재 유무 를 알려주는 flag이며, MVD는 참조영상과 현재영상과의 움직임 정보에 대한 차이 값이다. $\mathrm{HEVC}$ 부호화 과정에서 예측과정을 수행하는 중에 잔차신호 없이 예측이 아주 잘 된 경우 $\mathrm{CBF}$ 의 값은 0 이 되며, 움직임 정보가 참조영상과 같다면 MVD 또한 $(0,0)$ 의 값을 갖는다. Yang은 이 방법으 로 기존 $\mathrm{HM}$ 에 비해 약 $30 \sim 40 \%$ 부호화 시간을 단축할 수
있었고 이 방법 또한 $\mathrm{HM}$ 에 포함되었다. Gweon[12]은 $\mathrm{CBF}$ 의 값에 따른 고속 $\mathrm{PU}$ 결정 방법(CBF Fast Mode Setting; CFM)을 제안하였으며, Choi, Yang의 방법과 마찬 가지로 $\mathrm{HM}$ 에 포함되었다. Gweon은 $\mathrm{CBF}$ 의 값에 따라 현 재 비용조사 중인 PU에서 다른 형태의 PU로 더 이상 비용 조사를 하지 않고 조기종료 하는 방법을 제안하였다. 즉 이 고속화 방법은 $\mathrm{CBF}$ 가 0 인 경우 더 이상의 가능한 $\mathrm{PU}$ 들을 검색하지 않고 일찍 종료시키는 방법이다. 이 방법으로 부 호화 수행 시간을 기존 $\mathrm{HM}$ 보다 약 40 50\% 정도 향상시켰 다. 상기에서 언급된 고속화 방법은 주로 $\mathrm{CU}$ 와 $\mathrm{PU}$ 에 국한 되어 있다. 앞서 설명한 바와 같이 $\mathrm{TU}$ 의 결정과정 또한 높 은 복잡도를 요구한다. 이를 해결하기 위해서 Choi[13]는 잔차신호의 개수로 $\mathrm{TU}$ 의 조사과정을 조기 종료하는 방법 을 제안하였다. 이 방법은 예측과정 이후 변환과정에서 잔 차신호의 개수가 3 개 이하이면 다음 깊이의 TU조사과정을 조기 종료함으로써 부호화 복잡도를 약 $30 \%$ 정도 감소시 켰다. 또한 Teng[14]은 상위깊이 TU와 하위 깊이 TU간의 $\mathrm{RD}-\operatorname{cost}$ 값으로 $\mathrm{TU}$ 의 조사과정을 조기 종료하는 방법을 제안 하였다. 이 방법은 상위깊이 TU의 RD-cost값이 하위 깊이 $\mathrm{TU}$ 들의 RD-cost값 보다 작다면 $\mathrm{TU}$ 의 조사과정을 조 기 종료한다. Teng은 이 방법으로 부호화 시간을 약 $49 \%$ 정도 감소시켰다. 본 논문의 목적은 $\mathrm{TU}$ 의 결정과정에서 발 생하는 부호화 복잡도의 감소이며, 이를 위해 Gweon의 방 법을 이용한다. Gweon의 방법에 기반하여, $\mathrm{CBF}$ 가 0 인 경 우, TU결정과정을 조기 종료시키는 알고리즘을 적용하여 부호화 복잡도 감소를 얻을 수 있다. 하지만 Gweon의 방법 을 그대로 적용한 경우 $\mathrm{CBF}$ 가 0 인 경우에만 $\mathrm{TU}$ 결정 과정 에서의 복잡도를 감소 시킬 수 있으며, 사용자가 설정한 양 자화 파라미터의 값이 작다면 $\mathrm{CBF}$ 의 값이 0 인 경우의 수가 급격히 감소하여 복잡도를 감소시키는데 한계를 갖는 단점 이 있다. 또한 Choi가 제안한 잔차신호 수에 의한 고속화 방법은 영상의 저주파 및 고주파 특성에 대해 고려하지 않 은 단점이 있다.

본 논문에서는 Gweon의 고속 부호화 방법을 TU결정과 정에 직접 적용했을 때의 단점과 Choi가 제안한 잔차신호 수에 의한 고속화 방법의 단점을 극복하여 보다 광범위한 경우에서도 부호화 복잡도를 감소시키기 위해, 고주파 및 
저주파 신호의 특성에 따라 0이 아닌 잔차신호가 존재하는 경우에도 잔차신호의 변환 계수 분포에 따라 TU 결정을 조 기 종료시킬 수 있는 방법을 제안한다. 일반적으로 임의 크 기 TU의 변환 계수가 고주파 성분 없이 저주파 성분만을 갖는 경우 이 블록은 비교적 잔차 신호의 변화량이 적고 에너지 집중도가 높다는 것을 의미하며 이러한 블록은 분 할되지 않을 확률이 높다. 따라서 마지막 0이 아닌 변환 계 수의 위치를 기반으로 블록의 에너지 집중도를 판단하고, 이에 근거하여 $\mathrm{TU}$ 결정을 조기 종료함으로써 부호화 복잡 도를 대폭 감소시킬 수 있는 방법을 제안한다.

\section{III. 부호화 복잡도 개선을 위한 고속 TU 결정방법}

\section{LNZTC(last non-zero transformed coefficient) 위치와 TU 분할 관계}

상기에서 기술한 바와 같이 TU는 대응되는 $\mathrm{CU}$ 크기로 부터 쿼드트리 구조로 분할을 하며 최적의 $\mathrm{TU}$ 크기를 조사 한다. $\mathrm{HEVC}$ 에서 $\mathrm{TU}$ 의 최대 깊이는 3 으로 정의되어 있다. 그림 3 과 같이 $\mathrm{TU}$ 는 대응 $\mathrm{CU}$ 크기로부터 깊이를 0 부터 3 까지 증가하며 쿼드트리로 분할하여 각각의 TU에 대한 비용 조사를 수행하게 된다. 이에 따라 깊이가 증가할수록
조사하는 $\mathrm{TU}$ 의 숫자가 급격히 많아지며, 각 $\mathrm{CU}$ 및 이에 대응하는 $\mathrm{PU}$ 에서 잔차신호를 검출한 후 $\mathrm{TU}$ 의 조사과정을 수행하므로 PU의 다양한 형태 전부에 대해 그림 3의 과정 을 반복적으로 수행하여야 한다. 따라서 TU의 조사과정은 상당히 많은 계산이 필요하며, 이로 인해 계산 복잡도가 과 도하게 증가한다.

본 논문의 목적은 각 $\mathrm{PU}$ 의 잔차신호 검출 후 최적의 $\mathrm{TU}$ 를 선택하는 과정에서의 복잡도 감소이다. 제안 방법의 기 본 아이디어는 에너지 집중도가 높은 TU의 경우 더 이상 분할되지 않을 확률이 높다는 실험적 결과를 이용한다. 즉, 각 $\mathrm{PU}$ 에서 잔차신호가 평활한 특성을 가지면 작은 편차를 갖게 되고, 이 잔차신호들을 주파수 영역으로 변환한 경우 저주파 영역으로의 높은 에너지 집중도를 갖는다. 상기와 같은 높은 에너지 집중도의 잔차신호를 갖는 $\mathrm{TU}$ 는 더 이상 분할하지 않을 확률이 높다. 에너지 집중도는 여러 가지 방 법으로 판별할 수 있으며 제안방법에서 잔차 블록의 에너 지 집중도를 마지막 0이 아닌 변환 계수(last non-zero coefficient ; LNZTC)의 위치로 판단한다. LNZTC의 위치는 간단한 방법으로 얻을 수 있을 뿐만 아니라 $\mathrm{HEVC}$ 의 엔트 로피 부호화를 위해 필요한 요소이므로, LNZTC의 위치를 구하는 과정은 $\mathrm{HEVC}$ 의 인코더에 추가적인 연산을 부가하 지 않는다.

제안 방법에서는 LNZTC를 얻기 위하여 HEVC의 스캐

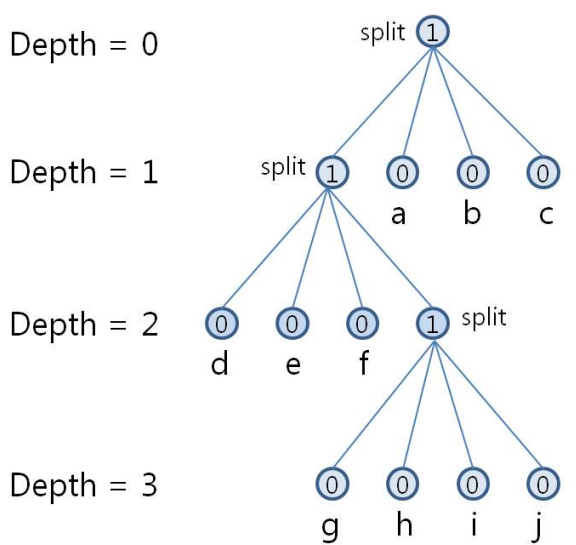

그림 3. TU의 쿼드트리 구조

Fig. 3. An example of HEVC TU quadtree

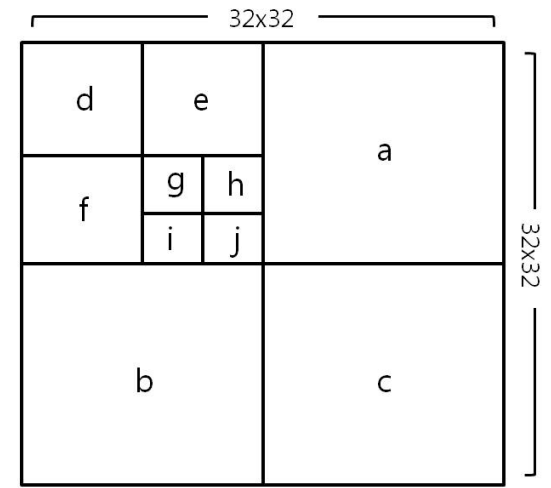




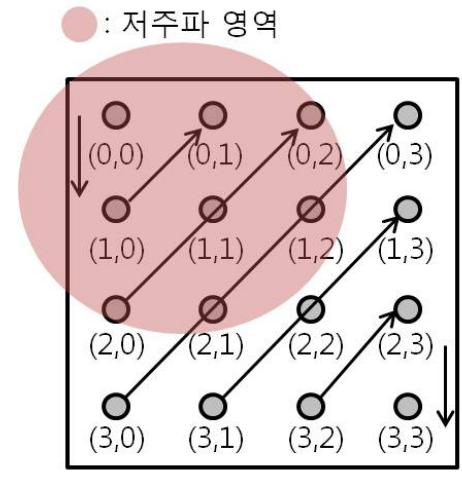

(a) Diagonal scan

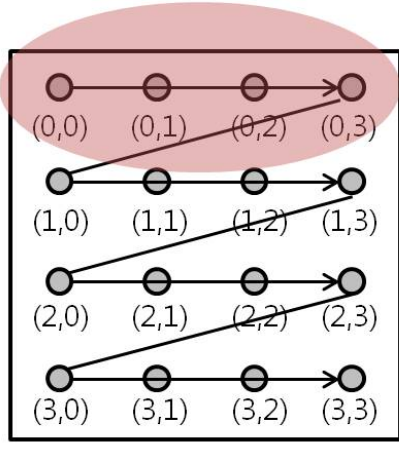

(b) Horizontal scan

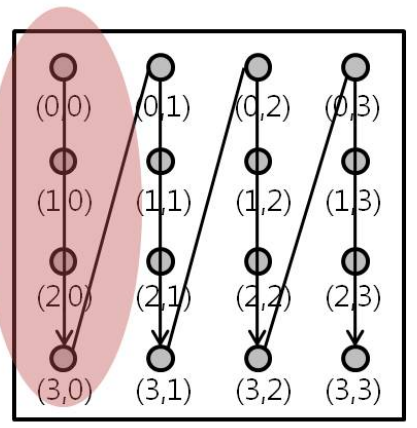

(a) Vertical scan

그림 4. HEVC 스캐닝 방식

Fig. 4. HEVC scanning orders for transform coefficients

닝 방식 ${ }^{[15]}$ 을 사용한다. 다음 그림 4 는 $\mathrm{HEVC}$ 의 스캐닝 방 식이다.

위 그림에서 Diagonal scan 방식은 Inter 모드로 예측했을 때 사용하는 스캐닝 방식이며 Horizontal Scan 및 Vertical Scan 방식은 Intra 모드로 예측했을 경우 추가로 사용되는 스캐닝 방식이다(즉 Intra 모드는 세 가지 방식 모두 사용한 다). 만일 임의의 변환 블록에서 LNZTC의 위치가 저주파 영역이라면 고주파 성분이 없는 것을 뜻하므로 이 블록은 비교적 평활한 영역이며 에너지 집중도가 높다고 판별할 수 있다. 따라서 현재 잔차블록의 에너지 집중도는 0 이 아 닌 변환계수의 위치로부터 알아 낼 수 있다. 다음의 표 1 은 LNZTC의 위치와 블록 분할간의 관계에 대한 통계적 분석 이다. 표 1 은 모든 가능한 크기의 $\mathrm{TU}$ 를 조사하고 최적의 $\mathrm{TU}$ 를 결정하는 기존 $\mathrm{HM}$ 을 이용하였을 때, LNZTC의 위 치에 따라 TU가 분할되지 않을 확률이다.

표 1에서 T는 양자화 과정 후 변환 블록에서 LNZTC의
위치이다. 표 1에서의 결과로 LNZTC의 위치가 그림 4의 저주파 영역에 위치할수록 TU가 분할되지 않을 확률이 높다. 이것은 앞서 기술한 에너지 집중도가 높을수록 하 위 블록으로 분할되지 않을 확률이 높다는 것을 증명하 는 지표이다. 따라서 LNZTC의 위치에 따라 블록의 분할 여부를 미리 판별 할 수 있다는 결론을 얻을 수 있다. 상 기와 같은 결과를 바탕으로 $\mathrm{TU}$ 결정을 조기 종료하여 부호화 복잡도를 감소시키는 알고리즘을 다음과 같이 제 안한다.

\section{2. 제안하는 고속 $\mathrm{TU}$ 결정방법}

$\mathrm{HEVC}$ 는 그림 2와 같이 순차적으로 여러 PU 형태들의 비용을 계산을 하고, 각 $\mathrm{PU}$ 에서 잔차신호를 생성한 후 잔 차신호에 대한 최적의 TU 크기를 결정하기 위해 재귀적으 로 하위 4 블록으로 분할하며 $\mathrm{TU}$ 에 대한 비용을 조사한

표 1. LNZTC의 위치에 따른 TU 분할 획률

Table 1. TU splitting probability according to the position of the last non-zero transform coefficient

\begin{tabular}{|c|c|c|c|c|}
\hline \multirow{2}{*}{ Test sequence } & \multicolumn{4}{|c|}{ TU가 분할되지 않을 확률 } \\
\cline { 2 - 5 } & $0<\mathrm{T}<=5$ & $6<\mathrm{T}<=10$ & $10<\mathrm{T}<=30$ & $\mathrm{~T}>30$ \\
\hline SteamLocomotive & 90.17 & 74.16 & 54.54 & 32.58 \\
\hline Kimono & 84.64 & 65.27 & 42.17 & 18.50 \\
\hline RaceHorsesC & 82.87 & 60.57 & 37.71 & 15.31 \\
\hline BlowingBubbles & 83.56 & 63.33 & 41.94 & 15.97 \\
\hline
\end{tabular}




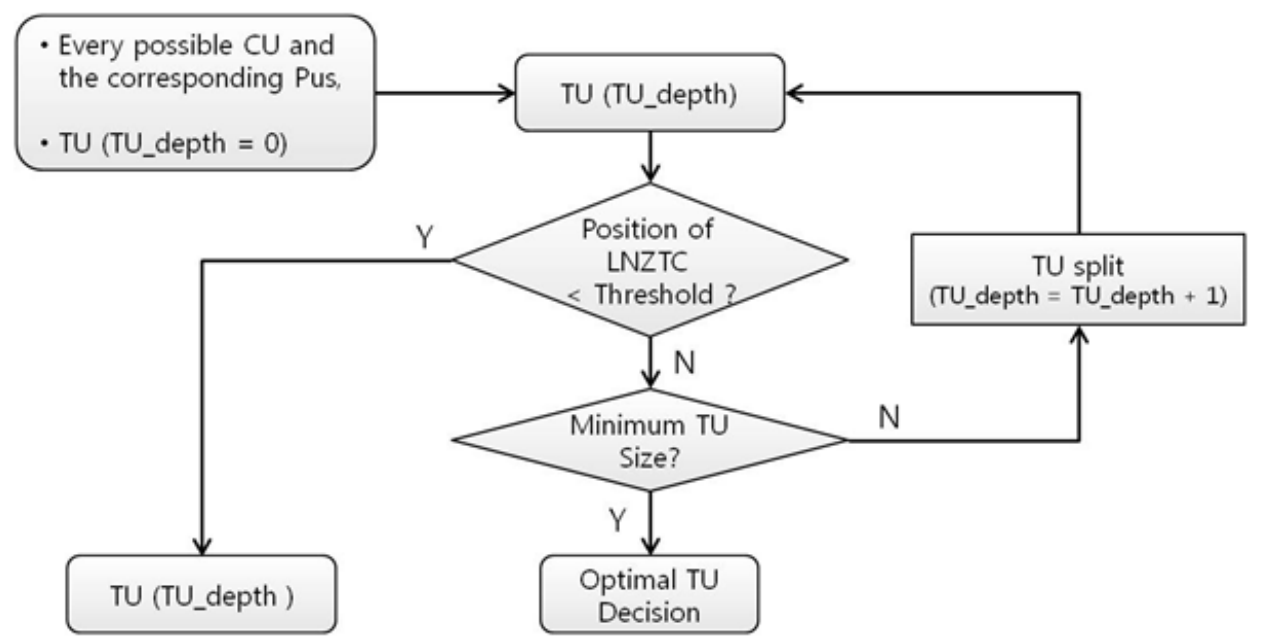

그림 5. 제안하는 고속 TU 결정방법의 흐름도

Fig. 5. A flowchart of the proposed fast TU decision

다 ${ }^{[16]}$. 이와 달리 제안 방법은 각 $\mathrm{PU}$ 의 $\mathrm{TU}$ 결정 과정에서 LNZTC의 위치에 기반 하여 하위 깊이 TU의 비용조사를 조기 종료할 수 있다. 만약 LNZTC의 위치가 저주파 영역 에 위치한다면 표 1 에 근거하여 하위블록으로 분할하지 않 고 조기 종료함으로써 부호화 복잡도를 개선할 수 있다.

그림 5 는 제안하는 고속 TU 결정 방법의 흐름도이다. 현 재 $\mathrm{CU}$ 와 그에 대응하는 임의 $\mathrm{PU}$ 를 이용하여 생성한 잔차 신호가 입력으로 주어진다. 그림 3과 같이 TU 쿼드 트리의 루트(root)는 현재 $\mathrm{CU}$ 의 크기이다. 따라서 첫 번째 $\mathrm{TU}$ 조 사를 위해서, 현재 $\mathrm{CU}$ 와 동일한 크기의 $\mathrm{TU}$ 를 이용하여 주 어진 잔차신호를 변환한 후 $\mathrm{TU}$ 의 에너지 집중도를 다음 식 (1)과 같이 조사한다.

$$
\operatorname{Pos}_{L N Z T C}\left(T U_{i, p}\right) \leq T
$$

여기서 $\operatorname{Pos}_{L N Z T C}$ 는 그림 4의 $\mathrm{HEVC}$ 스캐닝 순서에 따 라 LNZTC의 위치를 나타내며, $T U_{i, p}$ 는 TU 쿼드트리에서 의 $\mathrm{i}$ 번째 깊이 및 $\mathrm{p}$ 번째 $\mathrm{TU}$ 를 지칭한다. 만약 식 (1)를 만족한다면(즉 LNZTC의 위치가 임계치 이하라면) $T U_{i, p}$ 를 분할하지 않고 현재 $T U_{i, p}$ 의 크기로 $\mathrm{TU}$ 를 조기에 결정 한다. 반대로, $T U_{i, p}$ 의 LNZTC의 위치가 임계치보다 크다 면 TU 쿼드트리의 깊이를 1 증가시킨 후 하위 4 개의 $\mathrm{TU}$
$\left(T U_{i+1, p^{\prime}}\right)$ 로 분할한다. 분할된 $T U_{i+1, p^{\prime}}$ 각각에 대해 상기 에서 기술한 동일한 방법을 이어서 적용한다. 이 과정은 허 용하는 최소 크기의 TU가 될 때까지 반복적으로 수행한다. $\mathrm{HEVC}$ 에서 최소 크기의 $\mathrm{TU}$ 는 다음 식과 같이 정의 된다.

$$
M i n T U_{\text {size }}=\max \left\{T U_{\text {size }}\left(\operatorname{depth}_{M A X}\right), 4 \times 4\right\}
$$

여기서 $\operatorname{MinTU}_{s i z e}$ 는 허용하는 $\mathrm{TU}$ 의 최소 크기이다. 이는 HEVC 구문(syntax)으로 지정 가능한 최대 허용 깊이 값 depth $h_{M A X}$ 에서의 $\mathrm{TU}$ 크기와 $\mathrm{HEVC}$ 표준에서 허용하 는 변환 블록 크기인 $4 \times 4$ 중 큰 값으로 결정된다. 만약 최 소 크기까지 TU가 분할되었음에도 조기 종료가 되지 않았 다면, 기존 방법과 같이 그동안 비용조사를 했던 모든 TU 크기 중 가장 작은 비용을 갖는 TU 쿼드 트리 구조를 선택 하여 부호화한다. 이와 같은 고속 TU 결정 방법은 Intra 및 Inter 모드의 모든 PU 크기에 동일하게 적용할 수 있다.

결국 제안 방법은 식 (1)과 같이 미리 정의된 LNZTC의 위치에 대한 임계치에 의해 TU 분할을 조기에 종료함으로 써 복잡도를 감소시킨다. 그림 6 은 다양한 임계치를 이용하 여 제안 방법을 적용하였을 때, BD-RATE의 증가율에 대 한 실험 결과이다. 그림 6 의 그래프에서 세로축은 LNZTC 의 위치이며 가로축은 BD-RATE 증가율이다. 이 그래프에 


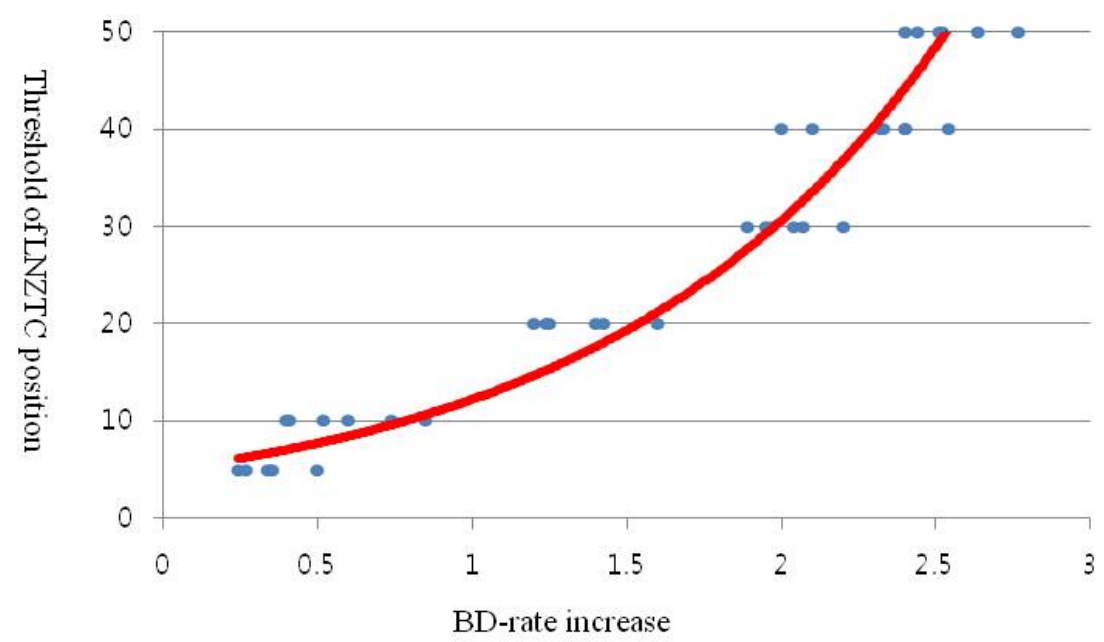

그림 6 제안 방법의 LNZTC의 위치에 따른 BD-rate 증가량

Fig. 6. BD-rate increase according to the threshold of the position of the last non-zero transform coefficient

서 보이는 것처럼, LNZTC의 위치가 고주파 영역에 위치할 수록 부호화 손실을 나타내는 BD-RATE가 증가한다. 이러 한 손실은 주로 TU 결정과정에서 율-왜곡 최적화 관점에서 는 분할해야 하지만 LNZTC의 위치가 임계치보다 적기 때 문에 강제적으로 분할되지 않음으로써 발생한다. 참고로 제안 방법은 LNZTC의 위치가 임계치보다 큰 경우, 강제로 분할을 시도하지는 않는다. 이러한 경우 상기에서 기술한 것처럼, 하위 깊이로 분할된 $\mathrm{TU}\left(T U_{i+1, p^{\prime}}\right)$ 들의 율-왜곡 비용 합과 큰 블록 크기를 갖는 상위 깊이 $\mathrm{TU}\left(T U_{i, p}\right)$ 의 율-왜곡 비용을 비교하여 분할을 결정하는 기존 방법을 따 른다. 따라서 그림 6 에서의 부호화 손실이 율-왜곡 최적화 관점에서는 분할되지 않아야 하지만 LNZTC의 위치가 임 계치보다 작기 때문에 강제로 분할을 허용하지 않는 경우 를 포함하지는 않는다.

결국 부호화 손실은 율-왜곡 최적화 관점에서는 분할되 어야 하지만 LNZTC의 위치가 임계치보다 작기 때문에 강 제로 분할하지 않은 경우가 부호화 손실에 영향을 미친다. 따라서 제안 방법에서는 임계치의 값 선택이 성능에 많은 영향을 미칠 수 있다.

본 논문은 LNZTC 적절한 화질보장과 높은 계산 복잡도 의 감소를 목적으로 한다. 따라서 위 그래프를 다음과 같이 모델링하여 적절한 LNZTC의 임계치를 계산한다.

$$
T=a_{1} \times e^{a_{2} \times B D R}
$$

식 (3)에서 T는 LNZTC의 위치에 대한 임계치이고, BDR 은 허용 가능한 BD-RATE 증가율이다. $a_{1}$ 과 $a_{2}$ 는 그림 6 의 결과를 토대로 임계치 값과 BD-RATE의 관계를 지수함 수로 모델링 했을 때 계수들이다. 그림 6의 실험 결과에 대 해 $\mathrm{SSE}$ (Sum of Square Error)가 가장 작도록 만들기 위한 $a_{1}$ 과 $a_{2}$ 의 값은 각 3.233 과 1.12 이다.

본 논문에서는 LNZTC의 위치에 대한 임계치를 허용 BD-RATE 증가율에 따라 결정한다. 따라서 제안방법은 식 (3)을 사용하여 BD-RATE 증가 허용 값에 적응적인 임계 치를 결정할 수 있다. 예를 들면 화질을 손해 보더라도 많은 복잡도를 감소시킬 필요가 있을 때 BD-RATE 증가율을 크 게 입력함으로써 임계치를 결정할 수 있다. 반대로 복잡도 보다는 화질이 우선적으로 높아야 할 경우에는 낮은 $\mathrm{BD}-\mathrm{rate}$ 증가율을 입력하여 작은 임계치 값으로 결정한다.

\section{IV. 실험 및 성능 검증}

실험에서 사용한 HEVC reference software 는 HM-7.0 [17]버전이고, 부호화 모드는 Random_Access_main, Intra 
main, Lowdelay_P_main이다(HM의 최신 버전은 HM- 11.0 이다. 그러나 TU 결정과정에서 큰 차이가 없어 연구를 시 작할 당시 최신 버전인 HM-7.0으로 실험하였다). 테스트 영상은 A, B, C, D Class 영상을 사용하였으며 실험 조건에 상기에서 설명한 $\mathrm{HM}$ 에 포함된 고속화 방법( $\mathrm{ESD}, \mathrm{CFM}$, $\mathrm{ECU})$ 들을 전부 포함시켰다. 그 외 나머지 조건은 $\mathrm{HEVC}$ 공통 실험조건 ${ }^{[18]}$ 에 따랐다. 부호화 시간 변화량 TS(Time Saving)는 다음 식을 이용하여 백분율로 나타내었다.

$$
\mathrm{TS}(\%)=\frac{T S_{r e f}-T S_{p r o b}}{T S_{\text {ref }}} \times 100
$$

여기서 $T S_{r e f}$ 는 HM-7.0 로 부호화 했을 때 소요시간 이 고, $T S_{p r o b}$ 는 제안한 방법을 HM-7.0 에 적용하여 부호화 했을 때 소요되는 시간이다.
표 2의 실험결과는 A, B, C, D 클래스 영상을 각각 All Intra, Random_access, Low_delay_P 모드로 부호화 했을 때, LNZTC의 위치가 0 부터 5 인 경우 하위 $\mathrm{TU}$ 로의 분할을 허용하지 않고 현재 크기의 TU로 결정하여 부호화 하며, 반대로 6이상인 경우에는 기존의 HM-7.0 방법에 따라 하 위 깊이로 분할된 $\mathrm{TU}\left(T U_{i+1, p^{\prime}}\right)$ 들의 율-왜곡 비용 합과 큰 블록 크기를 갖는 상위 깊이 $\mathrm{TU}\left(T U_{i, p}\right)$ 의 율-왜곡 비용 을 비교하여 분할여부 결정하므로써 얻어진 결과이며, 표 2 에서 임계치 5는 식(1)의 BD-RATE 증가량과 임계치간 의 모델에서 $\mathrm{BDR}$ 을 0.5 로 설정했을 때 얻은 임계치이다. 실험 결과 영상을 전부 Intra 모드로 부호화 한 경우 평균적 으로 약 $0.3 \%$ 정도의 미미한 $\mathrm{BD}-\mathrm{RATE}$ 증가가 있었으며, 복잡도의 척도인 $\mathrm{TS}$ 는 기존 $\mathrm{HEVC}$ 대비 약 $9 \%$ 가 감소하 였다. 마찬가지로 Low_delay_P 모드에서 제안방법을 적용

표 2. 제안방법의 부호화 효율 및 복잡도 감소 성능 실험 결과. 기준: HM 7.0

Table 2. Experimental results for the threshold of 5

\begin{tabular}{|c|c|c|c|c|c|c|c|}
\hline \multicolumn{8}{|c|}{ Threshold $=5$} \\
\hline \multirow{2}{*}{\multicolumn{2}{|c|}{ Sequences }} & \multicolumn{2}{|c|}{ Intra_main } & \multicolumn{2}{|c|}{ Low_delay_P } & \multicolumn{2}{|c|}{ Random_access } \\
\hline & & $\mathrm{BDR}(\%)$ & TS(\%) & $\mathrm{BDR}(\%)$ & TS(\%) & $\mathrm{BDR}(\%)$ & $\mathrm{TS}(\%)$ \\
\hline \multirow{4}{*}{ Class A } & Traffic & $0.5 \%$ & $8 \%$ & $0.3 \%$ & $17 \%$ & $0.5 \%$ & $18 \%$ \\
\hline & PeopleOnStreet & $0.4 \%$ & $9 \%$ & $0.6 \%$ & $15 \%$ & $0.6 \%$ & $16 \%$ \\
\hline & Nebuta & $0.0 \%$ & $9 \%$ & $0.2 \%$ & $14 \%$ & $0.2 \%$ & $17 \%$ \\
\hline & SteamLocomotive & $0.2 \%$ & $6 \%$ & $2.5 \%$ & $15 \%$ & $2.8 \%$ & $16 \%$ \\
\hline \multirow{5}{*}{ Class B } & Kimono & $0.2 \%$ & $7 \%$ & $0.7 \%$ & $15 \%$ & $1.0 \%$ & $15 \%$ \\
\hline & ParkScene & $0.2 \%$ & $8 \%$ & $0.9 \%$ & $16 \%$ & $0.5 \%$ & $17 \%$ \\
\hline & Cactus & $0.5 \%$ & $8 \%$ & $0.6 \%$ & $18 \%$ & $0.5 \%$ & $18 \%$ \\
\hline & BasketballDrive & $0.6 \%$ & $7 \%$ & $0.7 \%$ & $15 \%$ & $1.0 \%$ & $16 \%$ \\
\hline & BQTerrace & $0.5 \%$ & $8 \%$ & $0.5 \%$ & $16 \%$ & $0.5 \%$ & $16 \%$ \\
\hline \multirow{4}{*}{ Class C } & BasketballDrill & $0.7 \%$ & $9 \%$ & $0.7 \%$ & $18 \%$ & $0.4 \%$ & $21 \%$ \\
\hline & BQmall & $0.4 \%$ & $9 \%$ & $0.8 \%$ & $17 \%$ & $0.5 \%$ & $20 \%$ \\
\hline & PartyScene & $0.2 \%$ & $12 \%$ & $1.1 \%$ & $18 \%$ & $0.2 \%$ & $20 \%$ \\
\hline & RaceHorsesC & $0.3 \%$ & $8 \%$ & $1.0 \%$ & $16 \%$ & $0.9 \%$ & $20 \%$ \\
\hline \multirow{4}{*}{ Class D } & BasketballPass & $0.4 \%$ & $12 \%$ & $0.7 \%$ & $15 \%$ & $0.6 \%$ & $16 \%$ \\
\hline & BlowingBubbles & $0.2 \%$ & $12 \%$ & $1.4 \%$ & $19 \%$ & $0.3 \%$ & $19 \%$ \\
\hline & RaceHorses & $0.3 \%$ & $8 \%$ & $0.9 \%$ & $15 \%$ & $0.7 \%$ & $19 \%$ \\
\hline & BQSquare & $0.2 \%$ & $12 \%$ & $0.8 \%$ & $18 \%$ & $0.6 \%$ & $21 \%$ \\
\hline \multicolumn{2}{|r|}{ AVG } & $0.34 \%$ & $9 \%$ & $0.8 \%$ & $16 \%$ & $0.7 \%$ & $18 \%$ \\
\hline
\end{tabular}


표 3. 제안방법의 부호화 효율 및 복잡도 감소 성능 실험 결과. 기준: HM 7.0

Table 3. Experimental results for the threshold of 10

\begin{tabular}{|c|c|c|c|c|c|c|c|}
\hline \multicolumn{8}{|c|}{ Threshold $=10$} \\
\hline \multirow{2}{*}{\multicolumn{2}{|c|}{ Sequences }} & \multicolumn{2}{|c|}{ Intra_main } & \multicolumn{2}{|c|}{ Low_delay_P } & \multicolumn{2}{|c|}{ Random_access } \\
\hline & & $\mathrm{BDR}(\%)$ & $\mathrm{TS}(\%)$ & $\mathrm{BDR}(\%)$ & TS(\%) & $\mathrm{BDR}(\%)$ & $\mathrm{TS}(\%)$ \\
\hline \multirow{4}{*}{ Class A } & Traffic & $0.7 \%$ & $11 \%$ & $1.3 \%$ & $23 \%$ & $1.0 \%$ & $27 \%$ \\
\hline & PeopleOnStreet & $0.5 \%$ & $9 \%$ & $1.3 \%$ & $22 \%$ & $1.0 \%$ & $25 \%$ \\
\hline & Nebuta & $0.2 \%$ & $9 \%$ & $0.6 \%$ & $21 \%$ & $0.5 \%$ & $24 \%$ \\
\hline & SteamLocomotive & $0.3 \%$ & $9 \%$ & $3.5 \%$ & $21 \%$ & $3.2 \%$ & $24 \%$ \\
\hline \multirow{5}{*}{ Class B } & Kimono & $0.4 \%$ & $9 \%$ & $1.7 \%$ & $20 \%$ & $1.5 \%$ & $23 \%$ \\
\hline & ParkScene & $0.4 \%$ & $11 \%$ & $1.6 \%$ & $23 \%$ & $1.3 \%$ & $26 \%$ \\
\hline & Cactus & $0.5 \%$ & $9 \%$ & $1.4 \%$ & $23 \%$ & $1.4 \%$ & $26 \%$ \\
\hline & BasketballDrive & $0.7 \%$ & $9 \%$ & $2.1 \%$ & $22 \%$ & $1.9 \%$ & $26 \%$ \\
\hline & BQTerrace & $0.6 \%$ & $10 \%$ & $1.2 \%$ & $22 \%$ & $1.0 \%$ & $25 \%$ \\
\hline \multirow{4}{*}{ Class C } & BasketballDrill & $0.8 \%$ & $11 \%$ & $1.3 \%$ & $24 \%$ & $1.2 \%$ & $26 \%$ \\
\hline & BQmall & $0.5 \%$ & $10 \%$ & $1.5 \%$ & $23 \%$ & $1.2 \%$ & $26 \%$ \\
\hline & PartyScene & $0.4 \%$ & $12 \%$ & $1.6 \%$ & $24 \%$ & $1.5 \%$ & $29 \%$ \\
\hline & RaceHorsesC & $0.4 \%$ & $11 \%$ & $2.3 \%$ & $23 \%$ & $2.0 \%$ & $25 \%$ \\
\hline \multirow{4}{*}{ Class D } & BasketballPass & $0.5 \%$ & $13 \%$ & $1.6 \%$ & $21 \%$ & $1.2 \%$ & $22 \%$ \\
\hline & BlowingBubbles & $0.3 \%$ & $13 \%$ & $2.4 \%$ & $23 \%$ & $0.8 \%$ & $26 \%$ \\
\hline & RaceHorses & $0.4 \%$ & $10 \%$ & $2.0 \%$ & $23 \%$ & $1.4 \%$ & $25 \%$ \\
\hline & BQSquare & $0.4 \%$ & $13 \%$ & $1.9 \%$ & $25 \%$ & $1.2 \%$ & $31 \%$ \\
\hline \multicolumn{2}{|r|}{ AVG } & $0.5 \%$ & $11 \%$ & $1.7 \%$ & $23 \%$ & $1.4 \%$ & $26 \%$ \\
\hline
\end{tabular}

하였을 때 약 $0.8 \% \mathrm{BD}-\mathrm{rate}$ 증가로 $16 \%$ 정도의 복잡도 감 소를 얻을 수 있었으며, Random_access_main 모드로 부호 화 과정을 수행한 경우 약 $0.7 \%$ 의 BD-rate 증가로 $18 \%$ 정 도의 복잡도 감소를 얻을 수 있었다. 위 실험 결과와 같이 제안하는 방법은 미비한 객관적 화질의 증가만으로 복잡도 를 상당히 개선할 수 있었다. 표 3 은 임계치를 10 으로 실험 한 결과이며, 나머지 실험조건은 표 2 와 같다.

위 표 3에서의 실험 결과, 영상을 ALL_Intra 모드로 부호
화 한 경우 평균적으로 약 $0.5 \%$ 정도의 BD-RATE 증가가 있었으며, TS는 기존 $\mathrm{HEVC}$ 대비 약 $11 \%$ 가 감소하였다. Low_delay_P 모드에서 제안방법을 적용하였을 때 약 $1.7 \%$ $\mathrm{BD}-$ rate 증가로 $23 \%$ 정도의 복잡도 감소를 얻을 수 있었으 며, Random_access_main 모드로 부호화 과정을 수행한 경 우 약 $1.4 \%$ 의 BD-rate 증가로 $26 \%$ 정도의 복잡도 감소를 얻을 수 있었다. 표 2 와 표 3 의 결과는 상기에서 기술한 LNZTC의 위치가 고주파 영역일수록 BD-rate는 증가하며,

표 4. 제안 방법이 적용된 비율(hitting ratio) 및 제안 방법의 오류 확률

Table 4. Hitting ratio of the proposed method and approximate probabilities for wrong decision

\begin{tabular}{|c|c|c|c|c|c|c|}
\hline \multirow{2}{*}{$\mathrm{QP}$} & \multicolumn{3}{|c|}{ Nebuta } & \multicolumn{3}{c|}{ SteamLocomotive } \\
\cline { 2 - 7 } & $\begin{array}{c}\text { 전체 TU 중 LNZTC의 위치가 5 } \\
\text { 이하인 TU 비율 [\%] }\end{array}$ & $\mathrm{HM}-7.0[\%]$ & $\begin{array}{c}\Delta \\
{[\%]}\end{array}$ & $\begin{array}{c}\text { 전체 TU 중 LNZTC의 위치가 } \\
\text { 5이하인 TU 비율 [\%] }\end{array}$ & HM-7.0 [\%] & $\begin{array}{c}\Delta \\
{[\%]}\end{array}$ \\
\hline 22 & 12.30 & 12.10 & 0.20 & 76.42 & 74.47 & 1.95 \\
\hline 27 & 36.66 & 36.45 & 0.21 & 88.92 & 95.66 & 3.26 \\
\hline 32 & 63.90 & 63.58 & 0.32 & 93.93 & 92.17 & 3.76 \\
\hline 37 & 82.01 & 80.30 & 1.71 & 96.77 & 4.13 \\
\hline
\end{tabular}


반대로 복잡도는 감소하는 현상에 대한 지표이며, 따라서 제안방법은 $\mathrm{BD}-\mathrm{rate}$ 의 증가와 복잡도 감소와의 관계를 LNZTC의 임계치로 결정하여, 상황에 따라 적응적으로 복 잡도 감소를 얻을 수 있다.

표 4는 실험결과에서 가장 적은 BD-rate 증가율을 보 이고 있는 Nebuta 영상과 가장 많은 BD-rate 증가율을 보이고 있는 SteamLocomotive 영상에 대해 제안 방법이 올바른 TU 분할 결정을 했을 경우에 대해서 분석한 결 과이다.

표 4에서 각 테스트 영상의 첫 번째 열은 부호화 과정 중 전체 TU 개수와 LNZTC의 위치가 5 이하인 TU 개수의 비율을 나타낸다. 두 번째 열은 전체 TU 개수와 LNZTC의 위치가 5 이하이고 율-왜곡 최적화 관점에서 하위 블록으로 분할하지 않은 TU 개수의 비율을 나타낸다. 이 표에서 $\Delta$ 는 앞서 설명한 두 비율의 차이이다. 제안 방법의 경우 하위 블록으로 분할 가능한 TU가 임계치 5 이하면 항상 분할시 키지 않았다. 따라서 $\Delta$ 는 LNZTC의 위치가 5 이하인 TU 임에도 율-왜곡 최적화 관점에서 $\mathrm{TU}$ 분할을 결정할 때 하 위 블록으로 분할된 TU의 비율을 근사적으로 나타낸다. 다 르게 표현하면 $\Delta$ 는 제안방법을 적용하여 부호화 했을 때 그릇된 결정을 한 비율을 의미한다. 표 4에서 비교적 잔차 신호가 많은 Nebuta 영상의 경우 그릇된 결정 비율이 SteamLocomotive 영상의 경우보다 작다. 이는 표 2에서 Nebuta 영상이 SteamLocomotive 영상보다 부호화 손실이 더 적다는 것과 일치하는 실험 결과이다. 표 3에서 $\Delta$ 값 으로부터 (100- $\Delta$ ) 계산을 통해 바른 결정 비율(hitting ratio)을 얻을 수 있다. 이 표에서 보이는 것처럼, 제안 방법 의 바른 결정 비율이 $95 \%$ 이상임을 확인할 수 있다. 따라 서 표 3의 결과는 제안 방법이 표 2와 같이 미비한 부호화 손실로 높은 복잡도 감소를 얻을 수 있다는 것을 증명한 다.

또한 제안방법은 $\mathrm{CBF}$ 가 0 이 아닌 경우에서도 복잡도 감 소를 수행할 수 있는 장점이 있으며, 기존 $\mathrm{CBF}$ 에 의한 고속 부호화 방법과 결합하여 사용하여도 높은 부호화 복잡도 감소율을 얻을 수 있었다. 추가로 다른 임계치 값에 대한 $\mathrm{BD}-\mathrm{rate}$ 증가는 그림 6으로 확인할 수 있다.

\section{V. 결 론}

본 논문에서는 에너지 집중도가 높은 $\mathrm{TU}$ 의 경우 분할하 지 않을 확률이 높다는 실험 사실에 기반 하여 마지막 0 이 아닌 변환 계수의 위치에 따라 TU의 분할 여부를 결정하는 방법을 제안하였다. HM-7.0 환경에서의 실험 결과 Random_Access_Main 모드에서 $0.7 \%$ 의 미비한 객관적 부 호화 손실만으로 평균 $18 \%$ 의 계산 복잡도를 감소시킬 수 있음을 보였다. 또한 기존의 $\mathrm{CBF}$ 값으로 하위분할을 결정 하는 방법은 단순히 변환된 계수의 존재 유무만으로 하위 분할을 결정하는 반면 본 논문은 양자화된 변환 계수의 저 주파 및 고주파특성에 따라 적응적으로 임계치를 결정할 수 있으므로 영상의 특성에 따라 TU의 하위분할을 결정짓 는 것이 가능하다. 향후 양자화 파라미터 및 영상 특성에 따른 적응적인 임계치를 얻는 방안에 대한 추가적인 연구 가 필요하다.

\section{참 고 문 헌}

[1] Un-Ki Parka, Haechul Choi, Jung Won Kang, and Jae-Gon Kim, "Scalable Video Coding Using Large Block and its Performance Analysis," Journal of Broadcast Engineering, Vol. 18, No. 2, pp. 249-260, Mar. 2013.

[2] Sung-Ho Bae, Jaeil Kim, Munchurl Kim, Sukhee Cho, and Jin Soo Choi, "Assessments of Subjective Video Quality on HEVC-Encoded 4K-UHD Video for Beyond-HDTV Broadcasting Services," Broadcasting, IEEE Transactions on, Vol. 59, Issue 2, pp. 209-222, June 2013.

[3] Thomas Wiegand, Gary J. Sullivan, Senior Member, IEEE, Gisle Bjontegaard, and Ajay Luthra, Senior Member, IEEE, "Overview of the H.264/AVC Video Coding Standard," Circuits and Systems for Video Technology, IEEE Transactions on, Vol. 13, Issue 7, pp. 560-576, July 2003.

[4] JCT-VC, "High Efficiency Video Coding (HEVC) text specification draft 10 (for FDIS \& Consent)," JCTVC-L1003, Joint Collaborative Team on Video Coding (JCT-VC) 12th Meeting: Geneva, Jan. 2013.

[5] Joint Call for Proposals on Video Compression Technology, Document VCEG-AM91 of ITU-T Q6/16 and N113 of JTC1/SC29/WG11, Jan. 2010.

[6] JCT-VC, "High Efficiency Video Coding (HEVC) Test Model 11 (HM 11) Encoder Description," JCTVC-M1002, Joint Collaborative Team on Video Coding (JCT-VC) 13th Meeting: Incheon, Mar. 2013.

[7] JCT-VC, "Comparison of Compression Performance of HEVC Draft 9 
with AVC High Profile and Performance of HM9.0 with Temporal Scalability Characteristics," JCTVC-L0322, Joint Collaborative Team on Video Coding (JCT-VC) 12th Meeting: Geneva, Jan. 2013.

[8] Gary J. Sullivan, Jens-Rainer Ohm, Woo-Jin Han, and Thomas Wiegand, "Overview of the High Efficiency Video Coding (HEVC) Standard," Circuits and Systems for Video Technology, IEEE Transactions on, Vol. 22, Issue 12 pp. 1649-1668 Dec. 2012.

[9] Xiaolin Shen, Lu Yu and Jie Chen, " Fast Coding Unit Size Selection for HEVC based on Bayesian Decision Rule," Picture Coding Symposium(PCS), pp. 453-456, May 2012.

[10] JCT-VC, "Coding tree pruning based CU early termination," JCTVC-F092, Joint Collaborative Team on Video Coding (JCT-VC) 6th Meeting: Torino, July 2011.

[11] JCT-VC, "Early SKIP Detection for HEVC," JCTVC-G543, Joint Collaborative Team on Video Coding (JCT-VC) 7th Meeting: Geneva, Mar. 2013

[12] K. Choi, and E. S. Jang, "Early TU decision method for fast video encoding in high efficiency video coding," Electronics letters, Vol. 48, pp. 689-691, June, 2012.

[13] S.W. Teng, H.M. Hang, and Y.F. Chen, "Fast Mode Decision Algorithm for Residual Quadtree Coding in HEVC," in Proc. of IEEE Visual Comm. and Image Processing(VCIP2011), pp.1-4, Nov, 2011.

[14] JCT-VC, "Early Termination of CU Encoding to Reduce HEVC Complexity," JCTVC-F405, Joint Collaborative Team on Video Coding (JCT-VC) 6th Meeting Torino, July 2011.

[15] JCT-VC, "Mode Dependent Coefficient Scanning," JCTVC-D393, Joint Collaborative Team on Video Coding (JCT-VC) 4th Meeting: Daegu, Jan. 2011.

[16] JCT-VC, "Transform unit quadtree," JCTVC-C200, Joint Collaborative Team on Video Coding (JCT-VC) 3th Meeting: Guangzhou, Oct. 2010.

[17] High Efficiency Video Coding Test Model Software 7.0, Available: https://hevc.hhi.fraunhofer.de/svn/svn_HEVCSoftware

[18] JCT-VC, "Common HM test conditions and software reference configurations," JCTVC-I1 101, Joint Collaborative Team on Video Coding (JCT-VC) 9th Meeting: Geneva, May 2012.

\section{저 자 소 개}

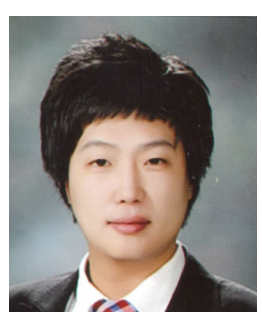

\section{강 장 병}

- 2012년 2월 : 한밭대학교 멀티미디어공학과 학사 졸업

- 2012년 3월 현재 : 한밭대학교 멀티미디어공학과 석사 과정

- 주관심분야 : HEVC, 고속 부호화, Multi-view Video Coding

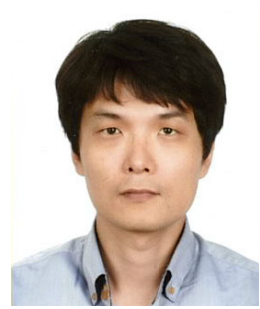

\section{최 해 철}

- 1997년 2월 : 경북대학교 전자공학과 학사

- 1999년 2월 : 한국과학기술원 전기및전자공학과 (공학석사)

- 2004년 8월 : 한국과학기술원 전기및전자공학과 (공학박사)

- 2004년 9월 2010년 2월 : 한국전자통신연구원(ETRI) 방송미디어연구부 선임연구원

- 2010년 3월 현재 : 한밭대학교 정보통신공학과 조교수

- 주관심분야 : 영상통신, 비디오 부호화, 패턴 인식 